\title{
De ontwikkeling in de dermatologie mede in relatie tot de gezondheidszorg
}

Citation for published version (APA):

van de Staak, W. J. B. M. (1983). De ontwikkeling in de dermatologie mede in relatie tot de gezondheidszorg. Maastricht University. https://doi.org/10.26481/spe.19830429ws

Document status and date:

Published: 29/04/1983

DOI:

10.26481/spe.19830429ws

Document Version:

Publisher's PDF, also known as Version of record

\section{Please check the document version of this publication:}

- A submitted manuscript is the version of the article upon submission and before peer-review. There can be important differences between the submitted version and the official published version of record.

People interested in the research are advised to contact the author for the final version of the publication, or visit the DOI to the publisher's website.

- The final author version and the galley proof are versions of the publication after peer review.

- The final published version features the final layout of the paper including the volume, issue and page numbers.

Link to publication

\footnotetext{
General rights rights.

- You may freely distribute the URL identifying the publication in the public portal. please follow below link for the End User Agreement:

www.umlib.nl/taverne-license

Take down policy

If you believe that this document breaches copyright please contact us at:

repository@maastrichtuniversity.nl

providing details and we will investigate your claim.
}

Copyright and moral rights for the publications made accessible in the public portal are retained by the authors and/or other copyright owners and it is a condition of accessing publications that users recognise and abide by the legal requirements associated with these

- Users may download and print one copy of any publication from the public portal for the purpose of private study or research.

- You may not further distribute the material or use it for any profit-making activity or commercial gain

If the publication is distributed under the terms of Article $25 \mathrm{fa}$ of the Dutch Copyright Act, indicated by the "Taverne" license above, 
De on whkeling in de drratologio

mede in relatie tot de geardhedazors

\section{REDE}

Uitgesproken bij de anvarding

wan thet ambet ran Hoogleraar in de

Huta en Geslachtsiekten

atan de miksuriversited "himbure"

tee

Maatricht:

op whidag 29 aprd. 1983

doot"

Dr w.J.B.M. vin de Statk 
Milnher de Rector Magriricus,

Dames an Heren Leden yan het Uniwersteitsbestur,

Dane en Heren leden wan de Universiteitsrad,

Dames en Heren Hoogleraren, Docenten en Leden wan de Wetenschappelijke staf,

Dames en hemen Studenten en voorts Gij allen; die door Uw aanweigheid blijk gate wan Uw belangstelling.

Zeer gowardeme toethoorders,

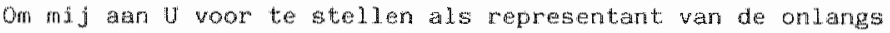
arn dez unjersiteit opgerichte capaciteitsgrowo dermatologie, wilde ik $U$ schetser min indeèn over de to verwachte ontwikkem ling in het specialigme huidakten wablj ik tevens wil betogen dat deze ontwikkeling de trend jijkt te volgen van de huicige bejeidswisie in de gezondheidszorg.

Bj.j eer bitk in de toekomst kan men niat voorbijgaan aan een vergei i.jking van het heden met het verleden.

De herismeringen an mijn earste ervaringen, nu ongeveer 25 jaar geleden, in een dernatologische universiteitskiniek, ziju de overvolde zalen van tientallen patiènten met woral ulcera cruras, psoriasis en diverse eczemen.

De ovemgrote ineenderhejd van de ulcera cruris zin zgn. veneuze

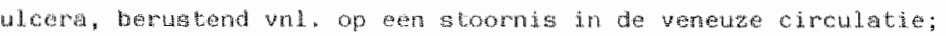
het is tegerwoordig an commots opinio det de behandeling van doze ulcera juist ambulant moet zijn met een vakkndig arage legd

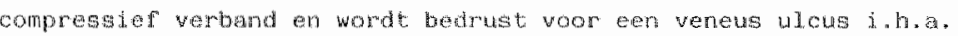
als een contra-indicatie beschowd.

De vrogere, wekenlange verpleging in een ziekenhus is derhatve heden ten dage wechts nodig voor ui tzonderlijke gevalier van ulcera crumis. 


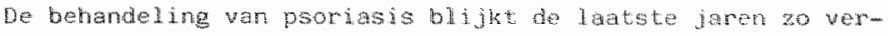

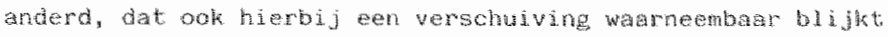
van de vroegere wekenlange, dure zakenhisverpleging nav een goedkope poliklinische therapia. ook hietin blijkt de dermatoloog de algemene trend in de gezonghed dargom het

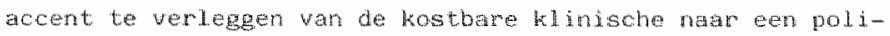
klirische behendeling als het ware automatisch te volgan. Bij de poliklinische begeleiding van psoriasispationten die vroeger op klinieche behandeling achgeweztan worth, han men tegenwoordig gebrulk maken van o. a. de zgn. PUWA-methode, vam

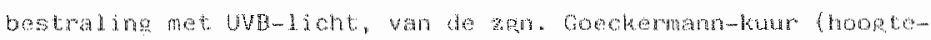
zombestraling na locale terbehmdeling en vam bopalde kum whet een cytostaticum, b.v een tabletenkum met frethothrexat. Voor al vam deze genoemde nethoden bestat een zekar indicatiegebied en zeker ate latat genoemde noet voorbehouden bijuen aan slechts en klein deel wan de meest emstige patizuten, hoewel ewt. complicaties ook bij deze methotrexazkuren - mits aen bepadde voorwarden wordt voldar - toch zelderi blijkus op te treden.

Bij de fotochemotherapie wan psoriasis, ook wel PUA genoend, volgt na inname - sons na locale toepassing - van psoraleenderitaten een bestraling met het langgolvige witrawiolette

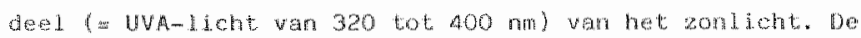

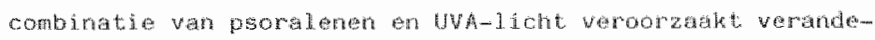
ringen in het DWh-molecul wardoor inhibitie van de DNAsynthese ontstat en een vertraging van de delingen var de

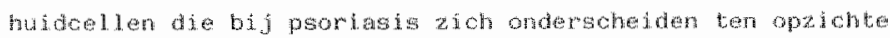
vam de nomale hid door een grotere intensivitelt van de celdellinger. 
Wast hat minder voorkomen van patienten met psoriasis en

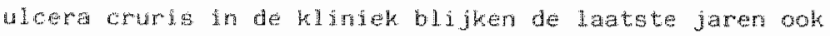

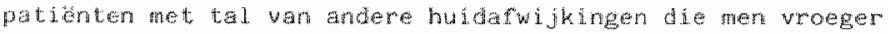
- en vadik in grote getale - aantrof op een dermatologische

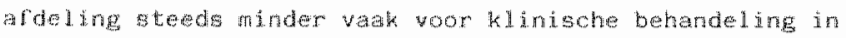
aenmerking te komen.

Aparta afdelingen vor baby"s, kleuters en wat oudere kinderen $x$ i ju san het werdwijnen. Betere behandehngsnogelijkheden van de hulsare en op de dermatologische poliklinieken maken dat

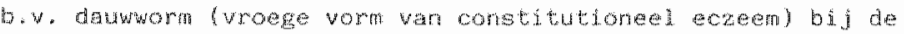
haby" a de datere nanirestatie van het constitutioned eczeen, everals ultgebreide huidinfectes (iryetigo, follicullitiden! steeds minder vask tot en ppnamemindicatie nopen. ook de parasitat muidinfecties zoals scabies pediculosis en strophulus die tegenwoordig nite minder fuequent woormomen, kunnen heden wri jwel altijd polikjimsoh effecter behandeld worden. Hetzelfde gelat voor de schimelinferties van de frudd.

ook de adollegcent met ernstige acne behoft tegenwoordig niet meer hekenlang - vaor 0.a. schilkuren - in de kliniek te verbijuen. De darwint van mer en betere therapeutische mogeIjkheden bij acne is deels het gevolg van een verbeterd in-

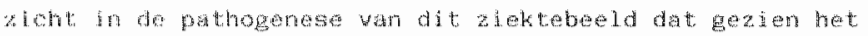
kometiseh efrect voor later - blifwende ljttekens bij shechte of geen behandxling - Jiefst 20 wroeg fnogelijk behandeld mowt

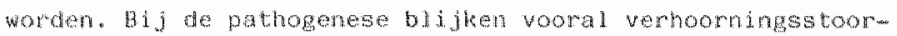
nissen, versterkte taleproduktie en lipasen-vorning door bepalde buterien en rol te spelen. 
Verhoorningestoom issen, onder invloed var andwogene homonen

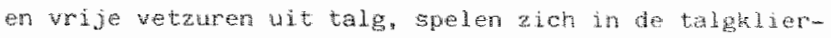

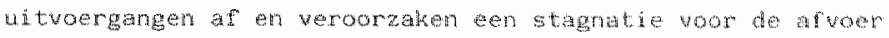

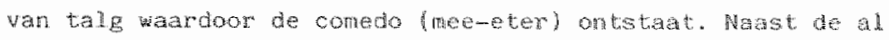
jeren bekende kematolytica - storfen die tegen aze abnormale verhoorring gericht zijn - zoals salicylzun en resorcine,

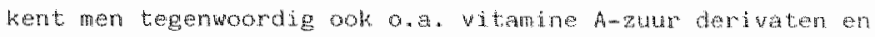
her benzoylperoxyde.

Om de talgproduktie te remen kan men bij wroukn - zeken indien deze boch al eten auticonceptiwum gebruken - in somige gevaluen goede resul taten kijgen wan ex combinatia (b.v. in de anticonceptie-pil, Biane) wan een oestrogentan homoon en een antiandrogen homon, roals cypoteronacetal Lipasen, gevormd wooral door de Propionibacterium acres, zouden uit talg wrije vetzuren wrimaken die in de huid van acne-patienten met name yerantwoordeljok zijn voor de vak errstige ontstekingen. Antibiotica, oral of local toegediend, onderdruken niet alleen de groes van genoemde bacterie maar hebber ook een antilipase werking wardoor de ontswekingen worden tegengegatan.

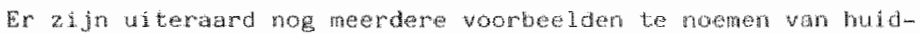
atuljkingen die op de kinderzalen wroeger bij patidntas rrequenter atu te trefren warer dar tegenwoordig door betere politelinitache behandeling, b.v. patienten fnet een vers de vela wormen wan ichthyosis (vissehuid), een stoormis in hat normale vertoomange proces wan de hujd of wen andere verhoorningsanomalia de ziekte wan Darier he ayskratosis roldicularis). 


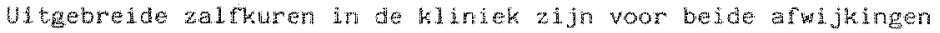
minder vak dan vroeger notig adngezien door meer wfecture en thus ook gemakkelijker copasbare utwendige therapie en indien nodig, sons tevens door oraal gebrilk war bepalde medicijnen (vitanine Awur deriwaten) de huid wan deze patignter in een betere conditie te houden is.

Op de zalen voor volwasemen treft men thegenwoordig onk andere

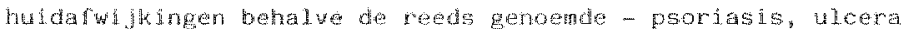
cruris warvoor het zeer dudelijk is - minder frecuert aan dan vroeger zoals eczeem van utentopende aetiologie, maligne retoulosen, pemphigus, sexuet overamagbare abrdoeningen (Soh). erythodermieen e. a voor deze ziektebelden die heden zeker niet minder frequet workonen daru vroeger geldt dat door ean betere polthlintsche behandeling langdurtge opname in de kliniet niet of soms gedurende slechts en korte tija nodig is. Behalve betere behandelingmogen i jkheren maben met nama bij eczeempatjenten sterk verbeterde onderzoktechieken, o.a. zogenaarde lapjes-(plak)proeven bij contacteczermen, er zeker toe bijgedragen dat de oorzagk van dezr huddaf ijking poliklinisch mu vaker achterhald en het aczesm niet klinisch behandeld behoert

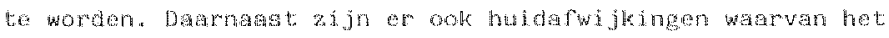

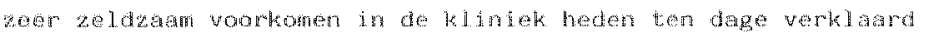

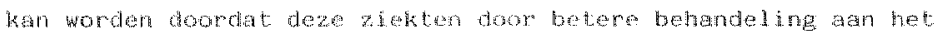
verdwijnen zijn b.w. de vele vormen varthuidtuberculose. 
De behandeling van malighe reticulosen, wamwan moosts fungoides de belangrijkste representant js, is thans radanig, dat deze nhet algemeen grotended polikinisch of thus gedaan kan worden.

Mycosis fungoides is een hwidnaligntest die tegenwoordig beschouwd wordt als en cutaan T-cel lympom warbij de in een thaligne cel veranderde T-Jymeoyt wellicht het gevolg is vam een voortdurende reactie op een nog onbekend antigeen. Dit antigen zou aanleiding kunnen geven tot en reactie wan de m-iymfocyter met als gevolg een ontregeld immunsystegrn en en verandering wan de T-1ymfocyt in een maligne cel. kinisch worder van oudsher 3 stadia onderscheiden:

1. premycotische stadiun. In dit stadiun vertoont de patiant weing woor deze reticulose specirive afwjkingen mar b.v. gedurende lange tijd, sons enige jaren, sterk jeukende op eczem of psoriasis gelijkende beelden;

2. het infiltratieve stadium warbij de huiderwijkingen verheven worden, rood of roodbruin van kleur en oval, guitrlande... of hoefj.jzervormig;

3. het tunor-stadium warin uit de infiltraten $x$ ich tumoren cntwikkelen die kunnen gaan ulceren wardoor in het eindstadiun de huid bezalid met necrotiserende tumoran kan geraken.

In het verloop van de ziekte kan witheiding nat lymphkiteren en interne organen optreden. 
Wa de hudage therpple betrert beperkt men zich in het

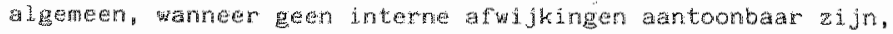

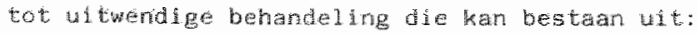

1. totale huldbestraling met snelle electronen. De bestraing wordt poliklindsch in de regel tuesmad per week gegeven, gesurende \pm 10 weken:

2. Witwentige applicatie van stakstofhosterd. De behandeling than op de polikliniek maar vaak ook door de pationt zelf thuie gedam worden.

3. fotochemotherapie (PUVA). Herbij wordt, net als bij psomasis, de hud \pm 2 uur ra ingane van 8 methoxypsoralex met langgolvig ultraviolet lioht (UWA) bestrald:

4. Whendige therapie met corticosterolden. Bij teinig geinfiltreerde laesses turnen corticosterouden onder en plastic occlusief werbard vakt tiljonlang enig soulaas biecten.

Bi. onvoldoende effect wan én of combinaties van deze theraptem of bij interne al joungen kan men inwendje cytostatica geven b.v. de zgn. Moppuhur, bestande uit er combinatie van mitoxine, vineristine (oncowinh), procarbazine en prednison.

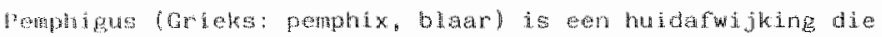
Gelknorkt word doom blatavoming. Ven de 4 variaten is

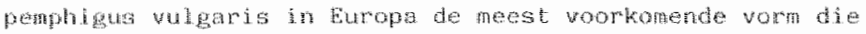
- Rort samengewat - zich manifesteer doov het rachiverend opteden van zear wherabele blaren de op de gehel nomal

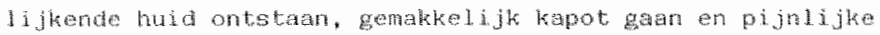
erestes worden. 


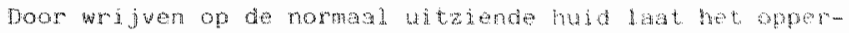

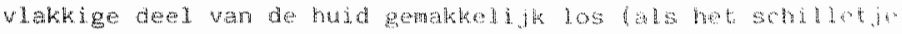

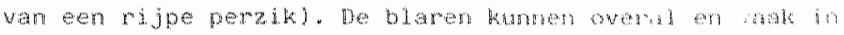

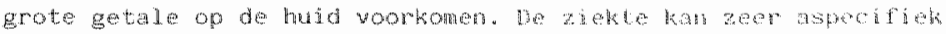

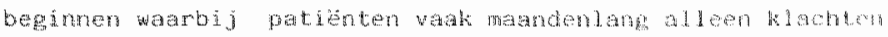

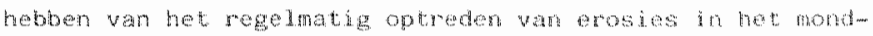

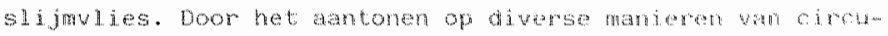

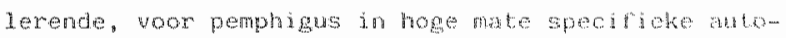

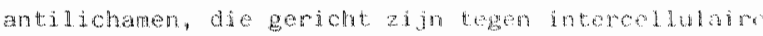

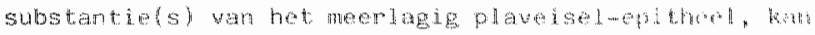

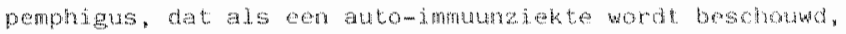

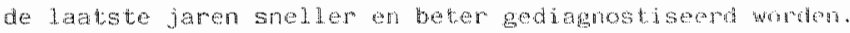

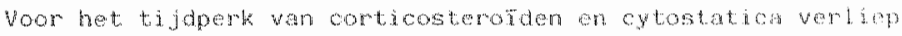

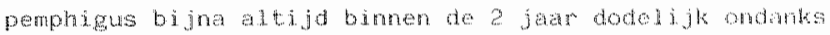

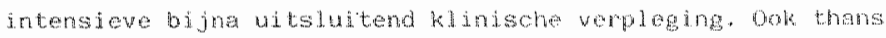

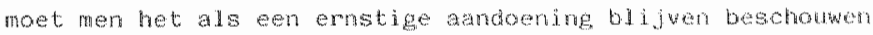

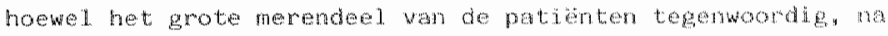

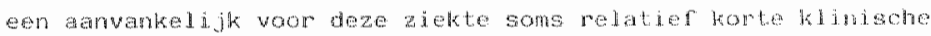
behandeding, jarenlang bij regelmatige polikinische contro in goede conditie te howaten ajn met en anvardband onder.m houdsdosering van de medicijnon.

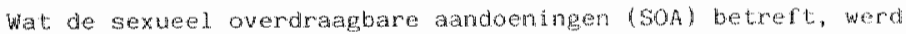

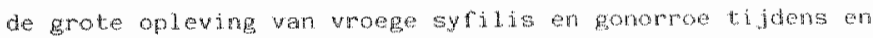

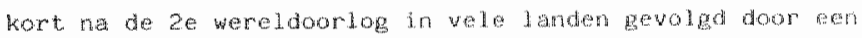

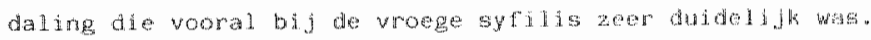

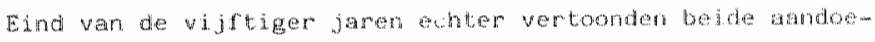

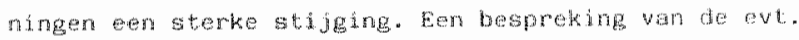

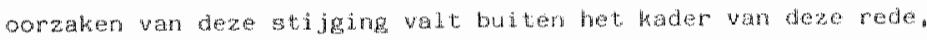

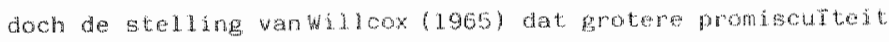
de grondonmak is wan deze problenat in is nog onverandera van kracht. 
ondanks zeer effect we benandalingsmethoden wordt toch

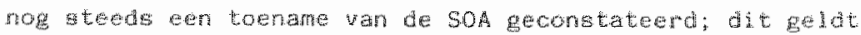
vooral woom gonorroe en in andere triate voor gyrilis.

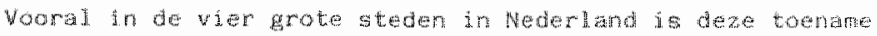

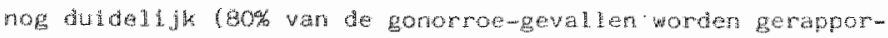
teerd in de wier grote stedem van Wederland; 40\% 5 n Amstendany. Deze tomane heert enter in de latute jaren geen dudelijk

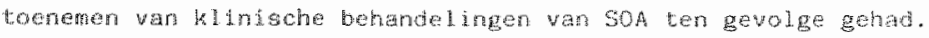
wor men woeger in de demetologische hisnok, zeker na do

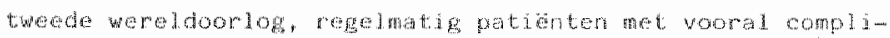

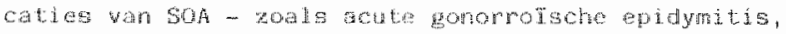

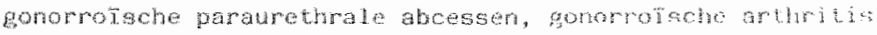

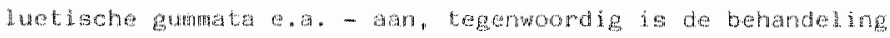

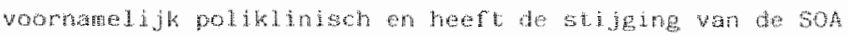

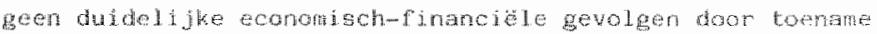
van zidkenhuisverpleging, wat ook in de toekomst niet te workachten is. Juist door utbreiding en verbetering in de

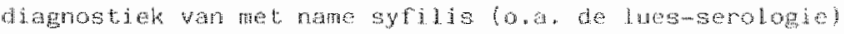
on door inspaning wan welen in de latste jaren voor betere bron-en contabopsoring en vootichting, kungen de afulikingon

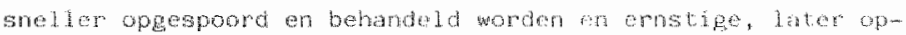

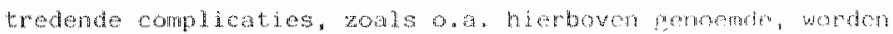
vookionen. Het blijuen netreven ool in de tonkenst wan modi?

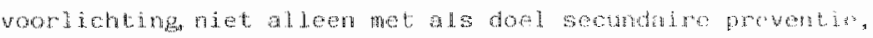

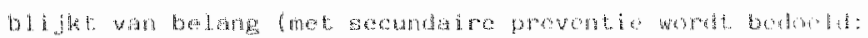

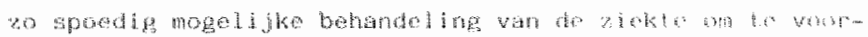

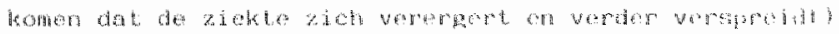

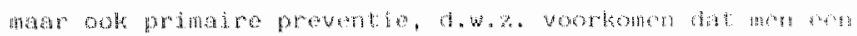

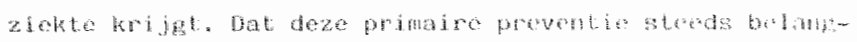

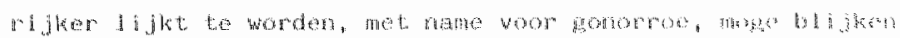

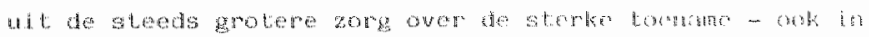

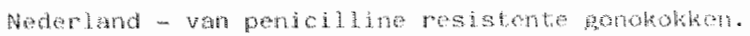


Waruit het butenland (V.S., Bamekok, whailand konen ook reeds berichten wan resistentie bekalve tegen peniciline

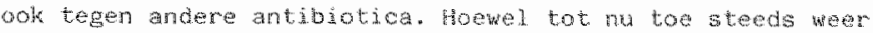
rilewe antibiotica konden worden ontwikkeld, groeit toch de werontrusting tot holang deze ontwktheling dere toename wan de resistentie het hoofd kan blijuen bieden.

Eenteryturodermie is eer ziektebeeld watrbij de getheles of magenoeg gehele huid rood is an meestul, schilferend. Woewel de rode huid warm arvoelt, heeft de patibnt het in de regel koud door warnteverlies. Het is dembalve bangrijk all do temperatur van de patient en de ongewing onder controle we houder on ondertemperatum of overhitung te voorkomen. Een erythrodernie is in reite op te vatten als een secundaife reactie, $d, z$, als een ulting van bijuoorbelid een in de regel

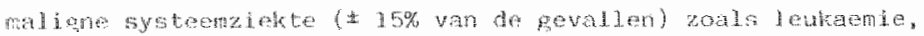
Howgkin, Iyrafosmooma, M. Sezary e.a. ofwel als wabraiding van een reeds bestaande hudarwijhing ( \pm 65\%), een toxischallergische reactie op geneesmiddelen ( 1 lo\%), terwijl soms ( $-8 \%$ het onderiggende lijden niet achterhald kan wordery.

De complicaties zijn woor est deel afhankelijk van de onden liggende oorzak van de erythodemie. Bi f alle emythrowernjedr achter bestagt het risico van secundaire infectie, hyper-or

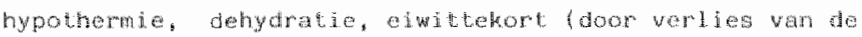
huidschifers) en uretoring in de mineraglhuighouding.

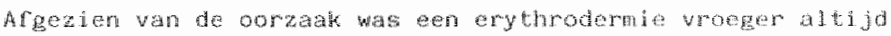

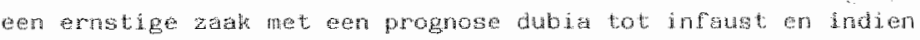
de pationt niet overled - de patienten gingen vak cachectisch met ernstige decubitus of door secundaire infectie fon grome was in de rege l een langrurige kinhsche behandeling nodig. 
Thares zijn de interne complicaties beter bekend en te be-

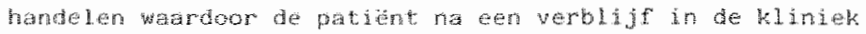
war hij ona op een bepalde therapia word ingesteld en zifl huid in een betere toestand is gebracht, wath weer whj shel ontslagen kan worden om poliklinisch met een onderhoudsdosering var de medici.jnen onder controle te

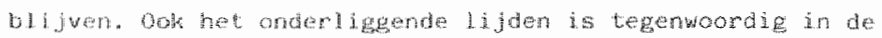

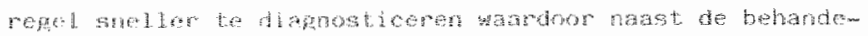

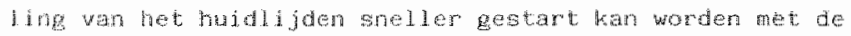

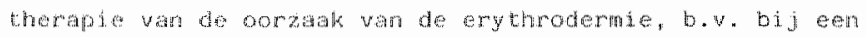

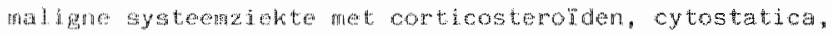
begtualing met róntgen of snelle elektronen e.a., bil en toxish-allengishe revetie op een geneesmiddel door het adves dit geneesmidel te staken of te vervangen doom een ander gelijkwaradig medicijn, to.

Wh hoop an de hand var genoemde voorbeeldere u duidelijk gemakt te hebben dat stimulering of dwhgerde matregelen van hogerhand om in het pakket van bezulnigungen van de gezondheidsarg reductie wan het dure ziekenhuisbed te bevorderen, woon de dematologie met moderne arinpak nauwe Hijks nodig zal zijn. Dat in de dermatologie - indien de wi da dartoe bestad - sterk bezuingh kan worden, meen ik te halen ult de getallen zie tabed die mij verstrekt worden varuit de dematologische praktijk in venlo warut een duidelijhe deling (tot $50 \%$ ) war klinische opnamen in

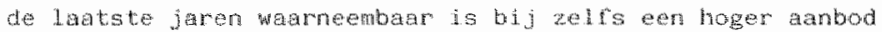
van patianten nagr dewe praktijk. 
Ook de hulp voor klebere, cosmetische hudproblemen lijkt

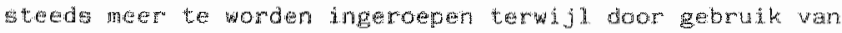
te wel en verkerde zepen (doucherris, badschuin "e.a.) wellicht ook dow te frequent baden vooral bi d oudere mensen.

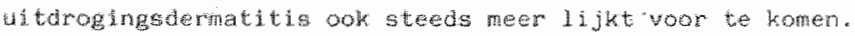
De toenane wan het vacantie houder en bezoken aan zonnige atrander door de meer zonambiddende, naoorloge generatie zall de frequentite van voortomen van hadearcinomen onder de nu ouder wordende bevolking doen toenemen.

Howel. matig alcoholgebruik als hartwersterker ger isen kan worden en ljjkt te begchermen tegen het krijgen var aen hartinfaret en on gezondiejebedenen njet onze arkeuring rechtvarorigt, noet het sterk toenemend alcoholgekruk tow zorgen barerh. Was het acoholgebruk per hoofu wan de bevolling in 1950, omgerekend naar pure alcohol, ongeveer 2 liter per jarr. in 1977 was dit al ruin 8 litem. De meeste probletmirinkers $(23,3 \%)$ in Mederland vindt men onder de linthirgse bewohking

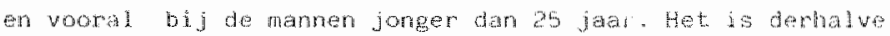
niet ondenkbaar dot beptalde huidarujkingen - o.a. zoals bohorende bij het ziektebeeld ponphymia cutanea tarda - dí het gevolg kumen zijn van langorig alcoholnisbruk in de torkonst zulary tomemen.

Howel het te verwachen is, dat behalve daze chkele gonomic voorbedden nog meerdere dermatosen in toenemende nace gezim

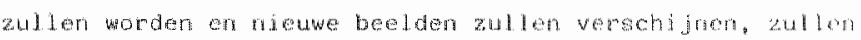

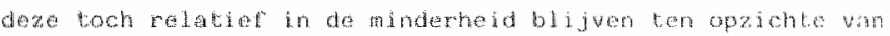

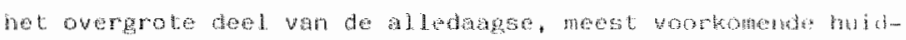

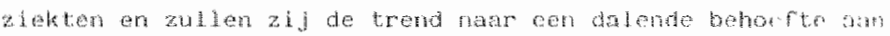

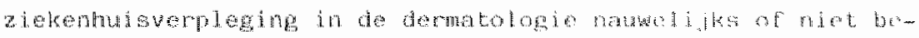

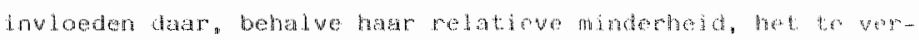

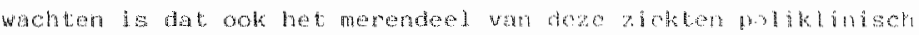
verholpen kan worder. 
Samenwatend han gesteld worden, dat het te verwachten is dat de verschuling in de latste jaren van kinische near polikinjsche behandeling van dematologische patienten in de taekonst eerder nog zal toem dan amenen. Een sterk kostenbesparend effect (nar grove schatting mear dan f $130.000 .000,-m$ per jaar) zal hiervan het gevolg ajn, temeer daar he niet aannemelijk is dat voor de te bieden polikingache hulp voor dermo tologische doeleinden ook in de toekotat zeor kostubar instrum mentarium weker in vergelijking met instrumentarium van de reeste andere medischa disciplinen - nodig zal zijn. 


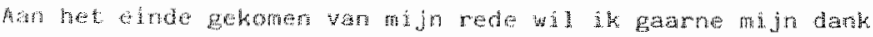

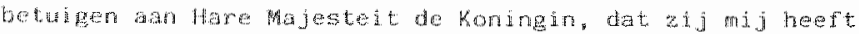
willen benomen tot hooglerar arn deze jonge Universiteit.

Mine lowes en heren leden van het universits tsbestum, van

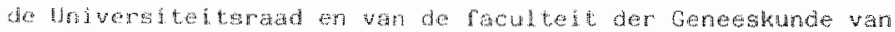

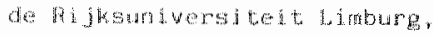

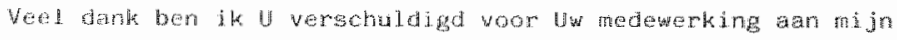
benoeming tot hoogherar in de dernatologie.

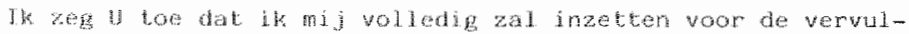

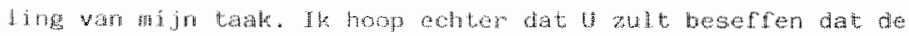
stiar dematologíg nog uit slechts enkelo leden bestad en zich voor do sonjer onogolijke taak gesteld zhet zich te wijden dan patiantconzorg, onderwijs en research op academigch nivean terwijl ow owerige facultaire faken en contacten met specialisten en huisartsen uit deze regio ons zeker ook zeer ter harte gan. Wi $j$ hopen dan ook in de toekmst op uw medewerking te kunnen rekenen ter u tbrejding wan destaf. Hot ig bedenkelijk dat atan den kinisch vak dat o.a. zo belangrijk is in welerlei opm ztoht woon hot onderwijs slechts $20^{\prime}$ k kein antal inedewerkers wordt toegeweren.

U kunt er ectier werackerd wan zijo dat desondanks de stat dermatolog zich volledig thet grote inzet zal boleggen op

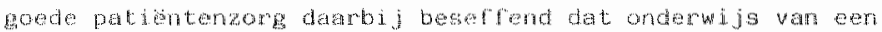
kinisch vak en research, vookwond wit hlinische problemetien zonder genvanceerde patientencorg niet mogeiljk is. 


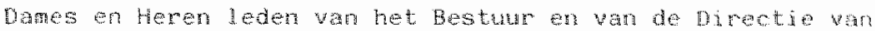

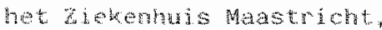

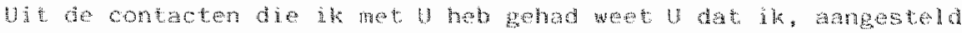

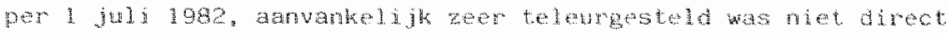

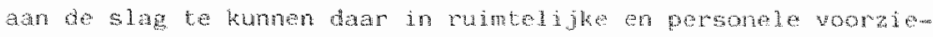

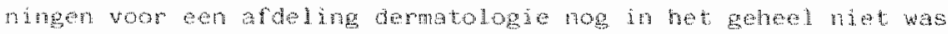

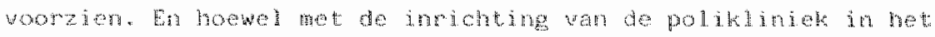

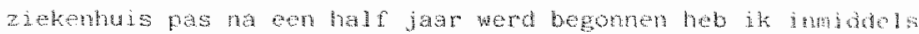

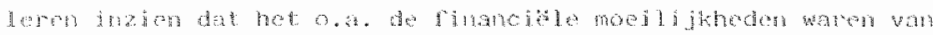

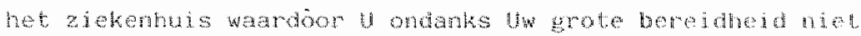

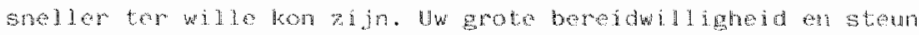

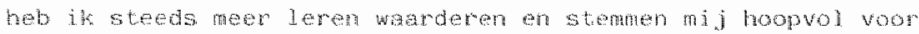

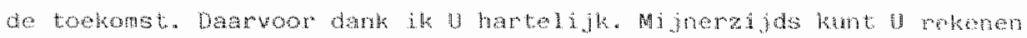

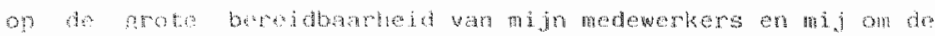

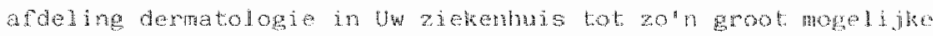
ontplooing te bremgent.

Moogeneleme Mali,

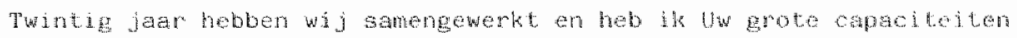

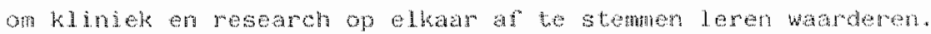

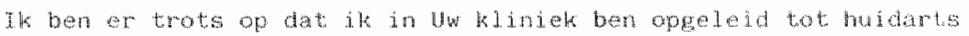

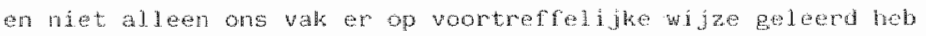

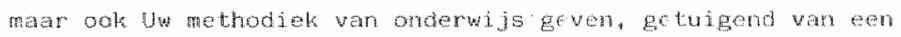
groot didactisch inzicht. Tevens ben ik u arikbar woor de voonl-

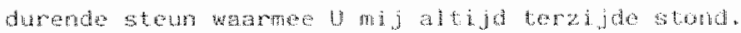

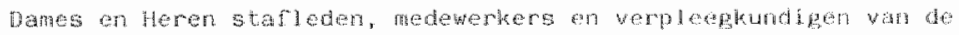

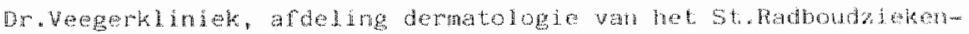
Futs te Ni jmegert.

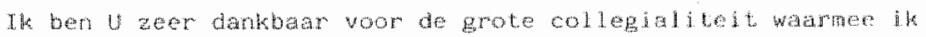

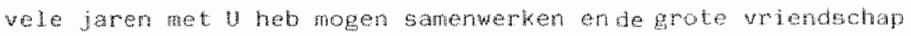
ate ik uan uncht ontuagen. 


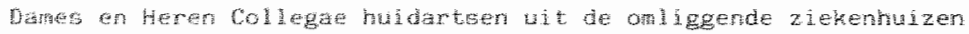

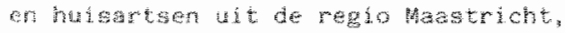

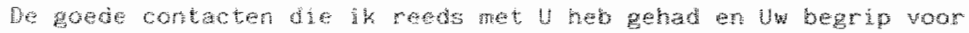
do moelifite ongtandigheden - met name de zer kleine staf van

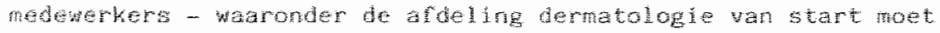
gear geven mid een groot vertrouwen in de toehonst. U kunt er

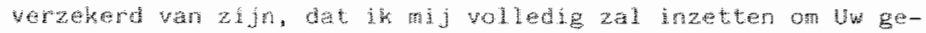
gewen vertrower in onze ardelang nit te beschamen.

Dames en Heren studenten,

De labete jaren heb ik het voormeht gehad de speciale onderwijsmethoduek wan daze Universiteit te volgun en was o.a. werschillende

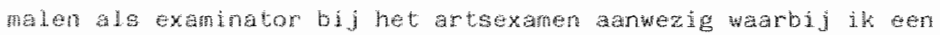
wergeitijting kon maken van Uw studieresultaten met de erveringen dis ik thet van he meer op traditie gescholde onderwijs. Ik neen

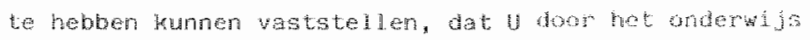
volgens het Mastrichtse model in een bevorrechte positie werkeert. Dat het probleer-geor ienteerde onderwijs, agrvankelijk door velen met cen zekere scepsis beschouwd, alon, ook in he buitenland" steads meer wardering krijgt is niet allew te danken aan de methare goede studieresul taten mar zeker ook an de grote inspaningen wan velen van $U$ w docenten. Ik weet dat $U$ - beserfende

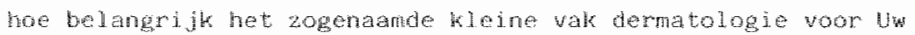
latere prektijkvoering als medicus is - verwehtingsvol uitgekeken heeft nar de start van de capacites tsgroep dermatologie

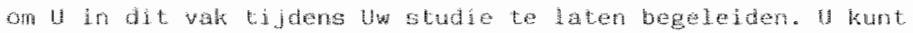

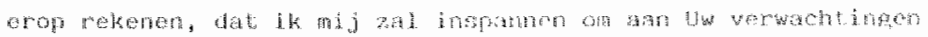

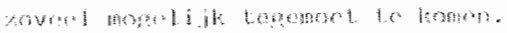

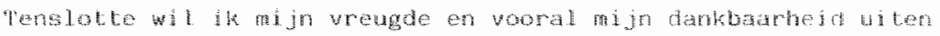

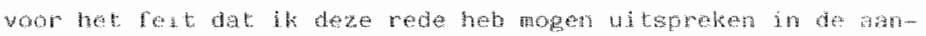

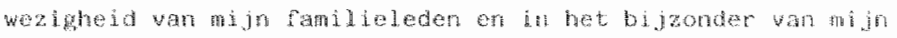

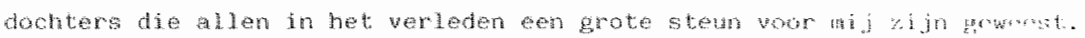




\section{Geradalegegde litteratur}

Cormane, A.H. and S.S.Asghar, current topies in i mithmology wol. IS. Immonology and skin diseases, Amold, 1981.

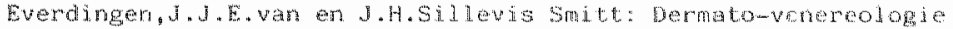
voor de eerste lijn. Stallen, Alphen an de tiju. 198h

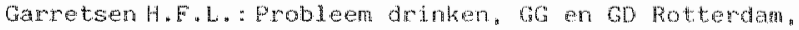
afd. Gvo, repport no 41,1982

Jansen,L.H.: Huid-en geslachtsaktan, 20 druk, Bohn, Scheltena en Holkema, Utrecht.

Rlokke,A.H., J.P.Nater, E. van Dijk en B.Stolz: Compendum huidm ziekten, Staflew, Aphen aan de Rijn. 1992

Knibbe, R.A.: Probleendrinken in Linburg, onderzoek in opdracht wan C.A. D. - Li mburg, 1982.

Knipschild, P.: Alcohol als hartversterker.

Hartbulletin, rebr. 1982.

Rook, A., D.5.WIlkirson, F. J.G. Ebling: Thex toook of drermatology.

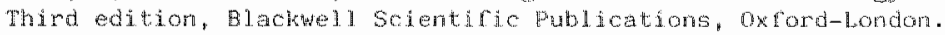

Stalz, E. en D. Surmond: Seksueel overdragbare andoningen. Starleu, Alphen ari de Rijn. $19 \mathrm{~g}$.

willcox, R.R.: Social aspects of wenereal diseases. Curr. Med.Drags. 5, 3, 1965. 


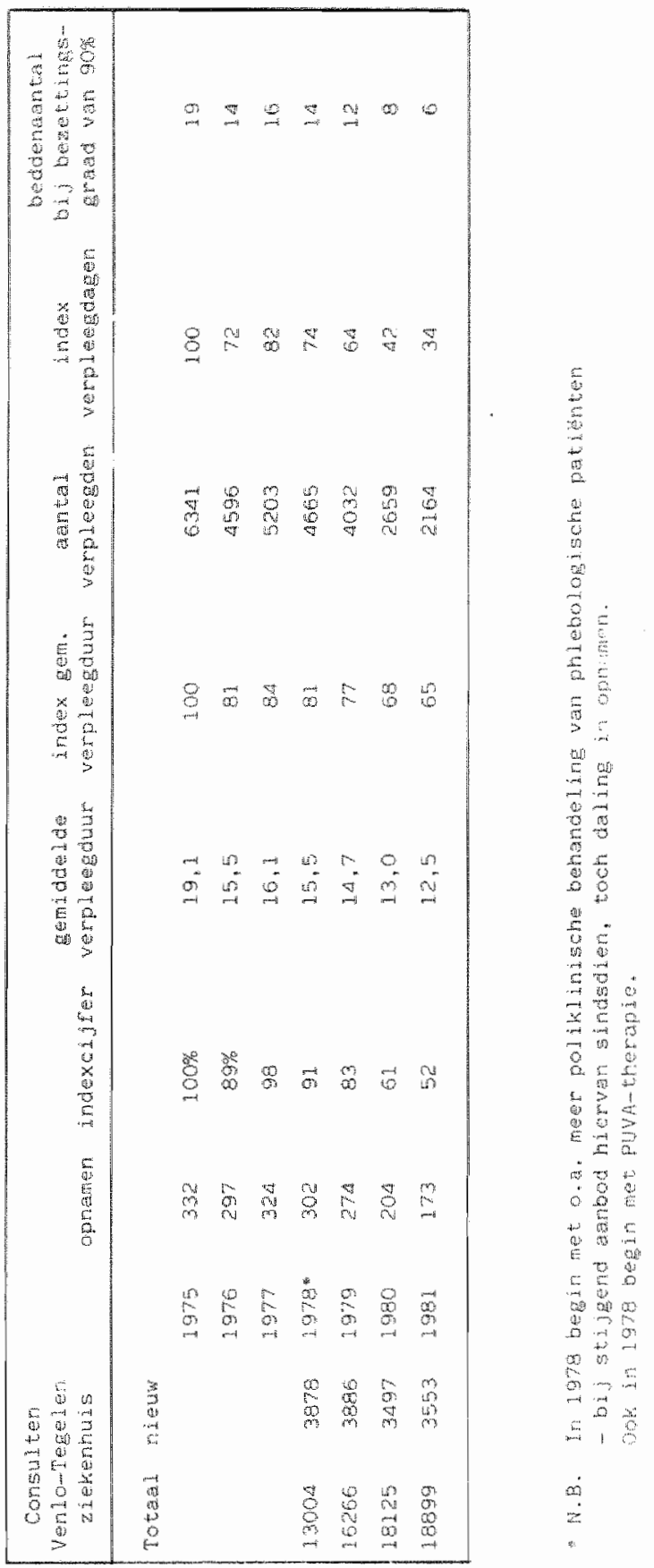

